\title{
Knowledge, attitude and practice of surgical staff towards preoperative surgical antibiotic prophylaxis at an academic tertiary hospital in Sudan
}

\author{
Ali Mohammed Ahmed ${ }^{1 *}$ (D, Sara Nasr ${ }^{1}$, Almegdad Mohamed Ahmed ${ }^{1}$ and Osama Elkhidir ${ }^{2}$
}

\begin{abstract}
Background: Surgical site infections (SSIs) are among the most common serious complications after surgery and associated with preventable morbidity, mortality, and increased health care costs. The use of surgical antimicrobial prophylaxis (SAP) is an effective measure that helps to protect against SSIs. This study aims to evaluate the knowledge, attitude, and practice of surgical staff towards preoperative antibiotic prophylaxis in surgery department at an academic tertiary hospital in Sudan.

Methodology: An observational descriptive study was conducted among doctors in the surgery department at an academic tertiary hospital in Sudan in order to assess their knowledge, attitude, and practice (KAP) towards surgical antibiotic prophylaxis (SAP). A four-section multiple-choice questionnaire was designed and hand-delivered to registered doctors in the surgery department at an academic tertiary hospital in Sudan. The WHO guidelines were used to evaluate the answers of the participants.

Results: Out of 56 doctors requested to participate in this study, only 49 responded and their response rate was $87.5 \%$. Six (12.5\%) surgeons had good knowledge about appropriate SAP. However, 16.3 and $24.5 \%$ of the respondents were aware of appropriate SAP in the case of Ig E-mediated reaction to penicillin and risk of Gramnegative infections, respectively. The surgeon's attitude score about the need for local and national guidelines for SAP was 98 and 100\%, respectively. Accordance of the physician's practice with ASHP guidelines regarding timing of the first dosage of SAP was $35.4 \%$ while correct administration of an intraoperative dose was $42.9 \%$ in agreement with the guideline. 53.1\% knows when to stop SAP after surgery correctly.

Conclusion: Although the participants in this study showed a positive attitude towards antibiotic prophylaxis guidelines, their knowledge and strict adherence to a protocolized practice per WHO checklist should be improved in order to reduce the incidence of preventable surgical site infections.
\end{abstract}

Keywords: Antibiotic prophylaxis, Knowledge, Attitude, Practice, Surgery, Surgeons

\footnotetext{
* Correspondence: ali.abusabib@gmail.com

${ }^{1}$ Faculty of Medicine, SAMER research group, Khartoum University, Alqaser

street, 11111 Khartoum, Sudan

Full list of author information is available at the end of the article
}

(c) The Author(s). 2019 Open Access This article is distributed under the terms of the Creative Commons Attribution 4.0 International License (http://creativecommons.org/licenses/by/4.0/), which permits unrestricted use, distribution, and reproduction in any medium, provided you give appropriate credit to the original author(s) and the source, provide a link to the Creative Commons license, and indicate if changes were made. The Creative Commons Public Domain Dedication waiver (http://creativecommons.org/publicdomain/zero/1.0/) applies to the data made available in this article, unless otherwise stated. 


\section{Introduction}

Surgical site infections (SSIs) are one of the most common postoperative complications, affecting nearly half of the patients undergoing surgical procedures [1]. Several studies have identified SSIs as a cause for increased morbidity, mortality, length of hospital stay, health care costs [2-7]. Due to various factors including lack of resources and staff shortage, the problem of SSIs is more prominent in developing countries [8].

Surgical antibiotic prophylaxis (SAP) has been recognized as one of the major factors and essential tools in combating and decreasing SSIs [9-12]. Numerous guidelines have been developed, describing the types, dosage, and duration of administration of SAP [13-15]. However, several studies have demonstrated poor adherence among doctors towards these guidelines [16-18].

A study conducted in Sudan revealed that the prevalence of SSIs was 25\% [19]. Although one study has concluded that there was a broad difference between the international guidelines and local practices in Sudan [20], there is a lack of sufficient evidence regarding doctors' knowledge and practices towards SAP guidelines. In this study, the aim was to assess knowledge, attitude, and adherence to the practice of SAP guidelines among doctors at an academic tertiary hospital in Sudan.

\section{Materials and methods}

This study was designed as a descriptive, facility-based cross-sectional study. Conducted at Soba University Hospital, which is the largest university hospital in the country, offering a wide variety of health services and educational training, with a capacity of 500 beds. All anesthesiology and surgery doctors, at all levels of training in the department of surgery at Soba University Hospital, were requested to participate in this study between December 2017 and January 2018.

The data regarding doctors' knowledge, attitude and adherence to practice towards surgical antibiotic prophylaxis was collected using a self-administered, foursection, multiple-choice questionnaire that was designed, reviewed, and used by Baniasadi et all at their study [21]. In addition to the first part of the questionnaire, which included demographic data about the doctor's age, gender, level of training, specialty, and level of training. It also has a second part, which was designed to assess doctors' knowledge about the types of surgeries in which SAP is used in, the antibiotics of choices which are commonly used in different clinical scenarios, and their source of knowledge regarding SAP. It also includes a third party in which the participants' attitude was evaluated towards preparation of national SAP guidelines, and their willingness to cooperate in the establishment of such guidelines. The last part of the questionnaire was dedicated to testing the adherence of doctors towards different SAP practices. Doctor's answers were considered correct when they were in alignment with the ASHP guidelines, which were developed by the Society for Healthcare Epidemiology of America, the Surgical Infection Society, and the Infectious Diseases Society of America [14].

The data were entered and managed using SPSS v23. Numerical data were presented as means and standard deviations (SD) and categorical data as frequencies and percentages. Pearson's correlation was used to test the correlation between participants' knowledge and practice towards SAP. While spearman's correlation was used to test the correlation between participants' level of training, and their knowledge and practice towards SAP. A $P$-value $<0.05$ was considered statistically significant.

This study was approved by the institutional review board at the department of community medicine in the faculty of medicine, University of Khartoum. Besides, written permission was sought from Soba University Hospital to conduct this study at their department. Moreover, consent was obtained from each respondent individually to participate in this study.

\section{Results}

56 doctors were asked to participate in this study, of whom $49(88 \%)$ responded to the questionnaire. More than half of the respondents 27 (55\%) were female, and their mean age was 26 years. Moreover, 25 (51\%) of the participants were specialty registrars at the time of the study, the vast majority of the $39(80 \%)$ were surgical registrars, and with a mean of 2 years as clinical-based practice experience. Table 1 demonstrates the demographic characteristics of the participants.

Regarding the knowledge of the participants about the types of surgeries in which SAP is administered, 41 (84\%) and $36(74 \%)$ of the respondents answered correctly by saying that SAP is administered for clean

Table 1 Demographic characteristic of the participants

\begin{tabular}{ll}
\hline Age mean (mean \pm SD) & $26.1 \pm 2.4$ \\
\hline Gender & $\mathrm{N}(\%)$ \\
Male & $22(45)$ \\
Female & $27(55)$ \\
Academic level & $\mathrm{N}(\%)$ \\
House officer (foundation trainee) & $22(45)$ \\
Medical officer (senior house officer) & $1(2)$ \\
Specialty registrar & $25(51)$ \\
Specialist & $1(2)$ \\
Specialty & $\mathrm{N}(\%)$ \\
Surgery & $39(80)$ \\
Anesthesiology & $10(20)$ \\
Years of experience (mean \pm SD) & $2 \pm 1.5$ \\
\hline
\end{tabular}


surgeries that involve prosthesis and clean contaminated surgeries, respectively. However, a major portion of the 40 (82\%) had chosen contaminated surgeries. Also, only $6(13 \%)$ of the respondents had correctly selected the drug of choice for Gastro-duodenal surgeries which is Cefazolin, while nearly half of the 23(48\%) selected ceftriaxone. Also, 8 (16\%) selected vancomycin or clindamycin as an alternative for patients with a history of Ig E-mediated reaction to penicillin. Conversely, a majority of them had correctly selected vancomycin as a drug of choice in cases of MRSA colonization. Concerning the sources of knowledge regarding SAP administration, textbooks and articles were the most selected, since 36 (74\%) had selected them. Table 2 shows the knowledge of respondents regarding varies aspects of SAP.

On the subject of hospital surgical antibiotics prophylaxis guideline, 48 (98\%) of the doctors have agreed that there is a need for a hospital guideline for surgical antibiotics prophylaxis. Additionally, 18 (37\%) of them said that they would be extremely cooperative in the establishment of hospital guidelines. While nearly half of the participants $24(49 \%)$ said that they will refuse to cooperate due to various reasons, including the workload 7 (14\%) and the lack of hospital guidelines in the hospital 16 (33\%). Likewise, all the participants believe that there is a need for a national surgical antibiotic prophylaxis guideline, and 19 (39\%) said that they are going to extremely cooperate for preparing that guideline. Nevertheless, 27 (55\%) of them said they will not cooperate in establishing a national guideline, 19 (39\%) said that because there are no national hospital guidelines, and only $7(14 \%)$ are going to refuse to cooperate due to the heavy workload.

About adherence of doctors practice with ASHP guidelines, only $10(20 \%)$ uses mechanical bowel preparation (MBP) in addition to oral antibiotics in elective colorectal surgeries, whereas the majority 21 (43\%) uses mechanical bowel preparation (MBP) only. Also, 17 (35\%) administer surgical antibiotics prophylaxis $60 \mathrm{~min}$ before the surgery. Yet, more than half of the 27 (55\%) administer SAP during the induction of anesthesia. Moreover, for antibiotics that require longer periods of admission before the surgeries like vancomycin and fluoroquinolones, $6(13 \%)$ of the respondents say that they administer these antibiotics 120 min before the surgery. On the other hand, nearly half of the 21 (43\%) said that during anesthesia induction is the perfect time to administer such types of antibiotics. 21 (43\%) of the participants repeat the dose of SAP in conditions like excessive blood loss more than $1500 \mathrm{cc}$, and when the operation's duration exceeds two half-lives of antibiotic. Table 3 demonstrates the adherence of doctors with

Table 2 Knowledge of respondents regarding varies aspects of SAP

\begin{tabular}{|c|c|}
\hline Questions & Response rate (\%) \\
\hline \multicolumn{2}{|l|}{ Types of surgery that require SAP: } \\
\hline Clean surgery involving the placement of prosthesis or implant. & $41(84)$ \\
\hline Clean non-prosthetic procedure. & $17(35)$ \\
\hline Clean-contaminated surgery & $36(74)$ \\
\hline Contaminated surgery & $40(82)$ \\
\hline Dirty surgery & $28(57)$ \\
\hline \multicolumn{2}{|l|}{ Accordance to the ASHP guidelines about SAP: } \\
\hline The 1st choice for SAP in Gastro-duodenal surgeries (GR: Cefazolin). & $6(13)$ \\
\hline For patients with a history of Ig E-mediated reaction to penicillin (GR: & $8(16)$ \\
\hline \multicolumn{2}{|l|}{ Vancomycin or clindamycin). } \\
\hline For procedures in which gram-negative pathogens are common (GR: & $12(25)$ \\
\hline \multicolumn{2}{|l|}{ Ciprofloxacin or Gentamycin). } \\
\hline For SAP in patients with Appendectomy for uncomplicated appendicitis & $35(71)$ \\
\hline \multicolumn{2}{|l|}{ (GR: Cefazolin + Metronidazole). } \\
\hline For MRSA colonization (GR: Vancomycin). & $40(82)$ \\
\hline \multicolumn{2}{|l|}{ Sources of knowledge regarding SAP administration } \\
\hline Textbooks and articles & $36(74)$ \\
\hline Knowledge from initial training & $25(51)$ \\
\hline Antibiotic prophylaxis guidelines & $12(25)$ \\
\hline Consultation with an infectious diseases physician & $11(22)$ \\
\hline Internet or personal experience & $31(63)$ \\
\hline
\end{tabular}


Table 3 Adherence of participants to ASHP guidelines

\begin{tabular}{|c|c|c|}
\hline Guideline recommendations & $\begin{array}{l}\text { Adherence N } \\
(\%)\end{array}$ & $\begin{array}{l}\text { Non-adherence N } \\
(\%)\end{array}$ \\
\hline \multicolumn{3}{|l|}{ Mechanical bowl preparation: } \\
\hline mechanical bowel preparation should be used in addition to oral antibiotics. & $10(20)$ & $39(80)$ \\
\hline \multicolumn{3}{|l|}{ Timing to administer parental prophylactic antimicrobials: } \\
\hline 30-60 min prior to surgical procedure. & $17(35)$ & $32(65)$ \\
\hline \multicolumn{3}{|l|}{ Timing to administer parental prophylactic antimicrobials that include vancomycin and fluoroquinolones: } \\
\hline 120 min before surgery. & $6(13)$ & $43(88)$ \\
\hline \multicolumn{3}{|l|}{ Conditions in which SAP dose is repeated: } \\
\hline $\begin{array}{l}\text { procedures that exceed two half-lives of prophylactic antibiotic or cause more than } 1500 \mathrm{~mL} \text { of blood } \\
\text { loss. }\end{array}$ & $21(43)$ & $28(57)$ \\
\hline \multicolumn{3}{|l|}{ Extension of SAP after surgery: } \\
\hline $24 \mathrm{~h}$ after surgery. & $26(53)$ & $23(47)$ \\
\hline
\end{tabular}

ASHP guidelines. Additionally, correlation between the academic level of participants and their practice, and between their knowledge and practice, was not significant $(p$-value $=0.6), \quad(p$-value $=0.8), \quad$ respectively. However, there was a significant correlation between doctors' knowledge and their academic level ( $\mathrm{p}$-value $=.02, \mathrm{CC}=$ $-0.33)$.

\section{Discussion}

The results of this study showed that there is a deficiency in doctors' knowledge regarding surgical antibiotics prophylaxis, especially in regards to the first line of choice in various clinical scenarios. Nevertheless, their attitude towards the need for national and local hospital guidelines was satisfactory, even though some of them said that they will not cooperate due to various reasons. Moreover, there was no association between the respondents' knowledge and their practice. However, they showed poor adherence to ASHP guidelines, particularly in areas related to timing of administration and mechanical bowel evacuation.

ASHP guidelines rank cefazolin as the first drug of choice for SAP in many surgeries [15], however in this study doctors' choice was ceftriaxone. In an audit conducted by Elbur et al. in Sudan, and despite the availability of cefazolin in the hospital, doctors reported using cefuroxime as their first choice [20]. Similarly, doctors' choices varied among different countries, cefazolin was selected first in Iran [21]. However, third and secondgeneration cephalosporins were doctors' choices in Turkey and Jordan, respectively [22, 23]. Moreover, cefazolin was selected in Canada, and co-amoxiclav in England [24, 25]. These variations might be due to many factors including differences in local guidelines, personal experiences, studies settings, and medication availability.

It is recommended that fluoroquinolones or aminoglycosides to be used if there is a risk of contamination with gram-negative bacteria $[15,26]$. In this study, only $25 \%$ of the participants selected these antibiotics. Similar results were found in a study from Iran, in which only $14 \%$ had adequate knowledge regarding this subject [21]. Furthermore, vancomycin usage as surgical prophylaxis has been recommended in cases of MRSA colonization [27]. 82\% of doctors correctly selected vancomycin in these cases, compared to $54 \%$ in another study [21]. This might be due to the numerous encounters of Sudanese doctors with MRSA colonization. For instance, a study conducted in a Sudanese tertiary state hospital revealed that nearly half of Staph Aureus specimens isolated from surgical wounds were methicillin-resistant [22]. Additionally, $82 \%$ of doctors in this study reported that SAP is used in contaminated surgeries. These results are coherent with other study from Jordan, in which doctors said that SAP should be used in contaminated surgeries [23]. However, in this situation, the guidelines clearly identify the usage of antibiotics as treatment and not as prophylaxis $[15,26]$. The majority of doctors in this study selected textbooks and articles as their major source of knowledge regarding SAP, this finding is similar to Al-Azzam et al. and Baniasadi et al. findings [23, 21].

Regarding the need for hospital and national SAP guidelines, doctors in this study showed a good attitude on the subject of establishing such guidelines. However, many of them said that they will not cooperate in preparing these guidelines due to the lack of other local and national guidelines. In contrast to this, doctors from other study had a good attitude towards the establishment of guidelines [21].

Only $35 \%$ of the study participants adhere to the practice of administering SAP 30-60 min before the surgery. Instead, the majority of them administer SAP during the induction of anesthesia, a method that has been proven to be less effective than the guidelines' recommendations [26]. Another study from Sudan also reported similar 
results, in which only $9 \%$ of its participants were adherent with this recommendation [20]. Analogous results were also revealed by Beer et al. [24]. On the other hand, a majority $74 \%$ of Baniasadi et al. study participants were adherent with this guideline [21]. Repeating intraoperative administration of SAP is endorsed in cases of excessive blood loss more than $1500 \mathrm{cc}$ or prolonged procedures [26]. In this study, only $43 \%$ of the participants were adherent to this recommendation. Harmoniously, only $40 \%$ of participant doctors from Iran adhere to this guideline [21].

This study had a limitation of a relatively small number of participants. However, it highlighted the lack of adequate knowledge and poor adherence to practice guidelines of surgeons regarding the topic of SAP. Adapting and preparing a national SAP guideline based on the epidemiology and susceptibility patterns of common pathogenic organisms is highly recommended. And institutionalization of such guidelines based on the specific data from every hospital is furthermore recommended. Also, nationwide studies are needed to identify the gaps in knowledge and practices of doctors. Furthermore, Implementation of these guidelines into practice is crucial, and thus, an institution-based training program about surgical antibiotics prophylaxis is extremely endorsed.

\section{Conclusion}

The current results revealed that the knowledge and practice of surgeons concerning SAP had some inconsistencies with the available scientific evidence. Effective educational programs and compiling local and hospital guidelines by a group of surgeons, clinical pharmacologists, and infectious disease physicians may improve SAP prescription and decrease SSIs.

\section{Abbreviations}

ASHP: American society of health system pharmacist; MBP: Mechanical bowel preparation; SAP: Surgical antibiotic prophylaxis; SSIs: Surgical site infections

\section{Acknowledgements}

The authors would like to acknowledge Dr. Mohammed Nasr Alshendawi for providing guidance and expertise towards finalizing this manuscript and Dr. Rawan Abdel Wahid for proofreading this paper.

\section{Availability of data and material}

All data generated or analyzed during this study are included in this published article [and its supplementary information files].

\section{Authors' contributions}

AM contributions is: to the conception, design of the work, analysis and interpretation of data. SN contributions is: the acquisition, analysis, and interpretation of data. AM contributions is: interpretation of data, have drafted the work. OE contributions is: analysis, supervision and substantively revised the work. All authors read and approved the final manuscript.

\section{Funding}

This research wasn't funded by any organization or pharmaceutical companies.
Ethics approval and consent to participate

Not applicable.

\section{Consent for publication}

Not applicable.

\section{Competing interests}

The authors declare that they have no competing interests.

\section{Author details}

${ }^{1}$ Faculty of Medicine, SAMER research group, Khartoum University, Alqaser street, 11111 Khartoum, Sudan. ${ }^{2}$ Department of community medicine, Faculty of Medicine, Khartoum University, Alqaser street, 11111 Khartoum, Sudan.

Received: 30 May 2019 Accepted: 5 December 2019

Published online: 11 December 2019

\section{References}

1. Anthony T, Murray BW, Sum-Ping JT, et al. Evaluating an evidence-based bundle for preventing surgical site infection: a randomized trial. Arch Surg. 2011;146(3):263-9.

2. Askarian M, Moravveji AR, Mirkhani $H$, Namazi S, Weed $H$. Adherence to American Society of Health-System Pharmacists surgical antibiotic prophylaxis quidelines in Iran. Infect Control Hosp Epidemiol. 2006;27(8): 876-8.

3. Blomstedt GC. Infection in neurosurgery: a restrospective study of 1143 patients and 1517 operations. Acta Neurochir. 1985;78:81-90.

4. Albright $\mathrm{L}$, Reigel DH. Management hydrocephalus secondary to posterior fossa tumours. J Neurosurg. 1977;46:52-5.

5. Green JW, Wenzel RG. Post-operative wound infections: a controlled study on the duration of hospital stay and direct cost of hospitalization. Ann Surg. 1977;185:264.

6. -Koek MB, Wille JC, Isken MR, Voss A, van Benthem BH. Post-discharge surveillance (PDS) for surgical site infections: a good method is more important than a long duration. Euro Surveill. 2015;20(8). Available from URL: http://www.eurosurveillance.org/ViewArticle.aspx?Articleld=21042. Accessed 1 Dec 2016.

7. Coomer NM, Kandilov AM. Impact of hospital-acquired conditions on fnancial liabilities for medicare patients. Am J Infect Control. 2016;44:132634.

8. -Agarwal M, Thomas P. Prevalence of post-op. Nosocomial infection in neuro-surgical patients and associated risk factors - a prospective study of 2441 patients. Nurs J India.2003;94:197-198, 212.

9. Hampson FG, Ridgway EJ. Prophylactic antibiotics in surgery. Surgery. 2005; 23(8):290-3.

10. Korol E, Johnston K, Waser N, Sifakis F, Jafri HS, Lo M, et al. A systematic review of risk factors associated with surgical site infections among surgical patients. PLoS One. 2013;8:e83743.

11. Burke JF. The effective period of preventive antibiotic action in experimenta incisions and dermal lesions. Surgery. 1961;50:161-8.

12. Bowater RJ, Stirling SA, Lilford RJ. Is antibiotic prophylaxis in surgery a generally effective intervention? Testing a generic hypothesis over a set of meta-analyses. Ann Surg. 2009;249(4):551-6.

13. -Scottish Intercollegiate Guidelines Network (SIGN). Antibiotic prophylaxis in surgery. Edinburgh: SIGN; 2008. (SIGN publication no.104). [2008]. Available from URL: http://www.sign.ac.uk/pdf/sign104.pdf. Accessed 1 Dec 2016.

14. Ozkurt Z, Erol S, Kadanali A, Ertek M, Ozden K, Tasyaran MA. Changes in antibiotic use, cost and consumption after an antibiotic restriction policy applied by infectious disease specialists. Jpn J Infect Dis. 2005;58(6):338-43.

15. Bratzler DW, Houck PM. Surgical infection prevention guidelines writers workgroup. Antimicrobial prophylaxis for surgery: an advisory statement from the National Surgical Infection Prevention Project. Clin Infect Dis. 2004; 38:1706-17.

16. Goede WJ, Lovely JK, Thompson RL, Cima RR. Assessment of prophylactic antibiotic use in patients with surgical site infections. Hosp Pharm. 2013;48: 560-7.

17. Hohmann C, Eickhoff C, Radziwill R, Schulz M. Adherence to guidelines for antibiotic prophylaxis in surgery patients in German hospitals: A multicentre evaluation involving pharmacy interns. Infection. 2012;40:131-7. 
18. Durando P, Bassetti M, Orengo G, Crimi P, Battistini A, Bellina D, et al. Adherence to international and national recommendations for the prevention of surgical site infections in Italy: results from an observational prospective study in elective surgery. Am J Infect Control. 2012:40:969-72.

19. Ahmed Ml. Prevalence of nosocomial wound infection among postoperative patients and antibiotics patterns at teaching hospital in Sudan. North Am J Med Sci. 2012;4:29-34.

20. Elbur Al, Yousif MA, Elsayed AS, Abdel-Rahman ME. An audit of prophylactic surgical antibiotic use in a Sudanese teaching hospital. Int I Clin Pharm. 2013;35:149-53.

21. Baniasadi S, Alaeen Z, Shadmehr MB. Surgical antibiotic prophylaxis: a descriptive study among thoracic surgeons. Tanaffos. 2016;15(3):154-9.

22. Hosoglu S, Sunbul M, Erol S, Altindis M, Caylan R, Demirdag K, et al. A national survey of surgical antibiotic prophylaxis in Turkey. Infect Control Hosp Epidemiol. 2003:24(10):758-61.

23. Al-Azzam SI, Alzoubi KH, Mhaidat NM, Haddadin RD, Masadeh MM, Tumah $\mathrm{HN}$, et al. Preoperative antibiotic prophylaxis practice and guideline adherence in Jordan: a multi-Centre study in Jordanian hospitals. J Infect Dev Ctries. 2012;6(10):715-20.

24. de Beer J, Petruccelli D, Rotstein C, Weening B, Royston K, Winemaker M. Antibiotic prophylaxis for total joint replacement surgery: results of a survey of Canadian orthopedic surgeons. Can J Surg [Internet]. 2009;52(6):E229-34. Available from: https:/www.ncbinlm.nih.gov/pubmed/20011156

25. Aiken AM, Haddow JB, Symons NR, Kaptanis S, Katz-Summercorn AC, Debnath D, Dent H, Tayeh S, Kung V, Clark S, Gahir J. Use of antibiotic prophylaxis in elective inguinal hernia repair in adults in London and southEast England: a cross-sectional survey. Hernia. 2013;17(5):657-64.

26. -Anderson DJ, Sexton DJ. Antimicrobial prophylaxis for prevention of surgical site infection in adults. In: UpToDate, Harris a (Ed), UpToDate, Waltham, MA. Accessed on March 25, 2016.

27. Madubueze CC, Umaru H, Alada A. Attitudes of Nigerian orthopaedic surgeons to the use of prophylactic antibiotics. Int Orthop. 2015;39(11): $2161-5$.

\section{Publisher's Note}

Springer Nature remains neutral with regard to jurisdictional claims in published maps and institutional affiliations.

Ready to submit your research? Choose BMC and benefit from:

- fast, convenient online submission

- thorough peer review by experienced researchers in your field

- rapid publication on acceptance

- support for research data, including large and complex data types

- gold Open Access which fosters wider collaboration and increased citations

- maximum visibility for your research: over $100 \mathrm{M}$ website views per year

At $\mathrm{BMC}$, research is always in progress.

Learn more biomedcentral.com/submissions 